\title{
Autofluorescence in freshly isolated adult human liver sinusoidal cells
}

\author{
Anett Kristin Larsen, ${ }^{1}$ Jaione Simón-Santamaría, ${ }^{1}$ Kjetil Elvevold, ${ }^{\text {* }}$ Bo Göran Ericzon, ${ }^{2}$ Kim Erlend Mortensen, ${ }^{3}$ \\ Peter McCourt, ${ }^{1}$ Bård Smedsrød, ${ }^{1}$ Karen Kristine Sørensen ${ }^{1}$ \\ ${ }^{1}$ Department of Medical Biology, UiT - The Arctic University of Norway, Tromso, Norway \\ ${ }^{2}$ Department of Clinical Science, Intervention and Technology (CLINTEC), Karolinska University Hospital, Stockholm, \\ Sweden \\ ${ }^{3}$ University Hospital of North Norway, Tromso, Norway \\ *Current address: The Norwegian Institute of Food, Fisheries and Aquaculture Research, Tromso, Norway.
}

\begin{abstract}
Autofluorescent granules of various sizes were observed in primary human liver endothelial cells (LSECs) upon laser irradiation using a wide range of wavelengths. Autofluorescence was detected in LAMP-1 positive vesicles, suggesting lysosomal location. Confocal imaging of freshly prepared cultures and imaging flow cytometry of non-cultured cells revealed fluorescence in all channels used. Treatment with a lipofuscin autofluorescence quencher reduced autofluorescence, most efficiently in the near UV-area. These results, combined with the knowledge of the very active blood clearance function of LSECs support the notion that lysosomally located autofluorescent material reflected accumulation of lipofuscin in the intact liver. These results illustrate the importance of careful selection of exogenous fluorophores, especially when labelling of live cells where the quencher is not compatible.
\end{abstract}

Key words: Autofluorescence; endogenous fluorophores; liver; endothelial cells; lipofuscin.

Correspondence: Anett Kristin Larsen, Department of Medical Biology, Faculty of Health Sciences, UiT - The Arctic University of Norway, PO Box 6050, Langnes, 9037 Tromsø, Norway, Tel. +47.95803933. E-mail: anett.k.larsen@uit.no

Contributions: AKL, JSS, performed the experiments; BGE, KEM, KE, provided human liver tissues and contributed to sample preparation; BS, PM, KKS, conceived the study; AKL, wrote the manuscript with the support from JSS, KKS, BS. All authors provided critical feedback and helped shape the manuscript.

Conflict of interest: The authors declare no conflict of interest.

Ethics approval and informed consent: Ethical approval of the study was granted by the Regional Committee for Medical and Health Research Ethics (REC ID 7065). All procedures followed were in accordance with the ethical standards of the Responsible Committee on Human Experimentation (institutional and national) and with the Helsinki Declaration of 1964 and its later amendments. Informed consent was obtained from all patients included in the study.

Availability of data: All data are available in the manuscript or upon request from the corresponding author. 


\section{Introduction}

Autofluorescence, the natural emission of light by biological structures, may possibly hamper fluorescence-based techniques if not properly addressed and corrected for. Several endogenous fluorophores are known to cause autofluorescence in many tissues, including liver. Autofluorescence in normal human liver tissue is predominantly caused by $\mathrm{NAD}(\mathrm{P}) \mathrm{H},{ }^{1}$ while vitamin $\mathrm{A}$ (vit $\mathrm{A}$ ) is known to contribute to the autofluorescence observed in hepatic stellate (Ito) cells. ${ }^{2}$ The fluorescent pigment lipofuscin accumulates in the lysosomes of many cell types with age and/or in patients with severe malnutrition and cancer cachexia ${ }^{3-5}$ and due to its broad excitation and emission spectra its presence complicates the use of techniques employing exogenous fluorophores. While most endogenous fluorophores have distinct spectral emission profiles, the spectra of lipofuscin overlap those of all commonly used exogenous fluorophores. ${ }^{6}$ This makes it difficult or even impossible to distinguish between specific labelling and autofluorescence caused by lipofuscin.

Liver sinusoidal endothelial cells (LSEC) rapidly change their morphology and function in culture and cell lines which retain the in vivo characteristics of these sinusoid lining cells are not yet available. ${ }^{7-9}$ Studies on the physiological function of these cells thus depend on isolation of primary cells from tissue samples. Several methods depending on fluorescence are often used to isolate, characterize, and investigate primary liver cells from human and animals. While autofluorescence in hepatocytes and stellate cells is well known, ${ }^{2,10,11}$ the presence of endogenous fluorophores in human LSEC is little known. In this study we aimed to characterize the observed autofluorescence in human LSEC and determine whether pretreatment with a lipofuscin autofluorescence quencher would allow for subsequent use of exogenous fluorophores.

\section{Materials and Methods}

\section{Human liver tissue and isolation of human liver sinusoidal endothelial cells}

Liver tissue was obtained from patients undergoing hepatic resection at the Department of Clinical Science, Intervention and Technology (CLINTEC), Karolinska University Hospital, Stockholm, Sweden or the University Hospital of North Norway (UNN), Tromsø, Norway. Patients included in the study gave informed consent and ethical approval of the study was granted by The Regional Committee for Medical and Health Research Ethics (REC ID 7065). Perfusion of human liver tissue resections has previously been described in detail. ${ }^{12}$ Only minor modifications were implemented, as described below. After cannulation, the tissue was washed using cold $\mathrm{Ca}^{2+}$ - and $\mathrm{Mg}^{2+}$-free Hanks Balanced Salt Solution (HBSS) followed by perfusion with warm $\left(37^{\circ} \mathrm{C}\right) \mathrm{HBSS}$ with $50 \mu \mathrm{g} / \mathrm{mL}$ ascorbic acid and $0.5 \mathrm{mM}$ EGTA. The tissue was then perfused with warm HBSS without additives to remove EGTA before 25-30 mg/L liberase ${ }^{\mathrm{TM}} \mathrm{TM}$ (cat.no: 05401127001; Roche, Basel, Switzerland) in $200 \mathrm{~mL}$ CBC buffer $(0.4 \% \mathrm{w} / \mathrm{v}$ $\mathrm{NaCl}, 0.025 \% \mathrm{w} / \mathrm{v} \mathrm{KCl}, 2.3 \% \mathrm{w} / \mathrm{v}$ Hepes, $0.26 \% \mathrm{w} / \mathrm{v} \mathrm{NaOH}$, $0.07 \% \mathrm{w} / \mathrm{v} \mathrm{CaCl}_{2}$ ) was recirculated until optimal tissue digestion. The cell suspension was filtered through $100 \mu \mathrm{m}$ sterile mesh and hepatocytes pelleted by centrifugation at $50 \mathrm{~g}$ for $3 \mathrm{~min}$ at $4{ }^{\circ} \mathrm{C}$. Non-parenchymal cells (NPCs), pelleted by centrifugation at $300 \mathrm{~g}$ for $5 \mathrm{~min}$ at $4{ }^{\circ} \mathrm{C}$, were fractionated using a $25 \% / 50 \%$ Percoll (cat.no: P1644; Merck, Darmstadt, Germany) gradient (1350 g, 25 $\left.\min , 4^{\circ} \mathrm{C}\right)$. The cells located at the interface between the two con- centrations of Percoll were subjected to positive selection using CD31+ magnetic microbeads (cat.no: 130-091-935; Miltenyi Biotec, Auburn, CA, USA). The images shown in the manuscript originates from 3 different patient samples, but autofluorescence was observed in all samples originating from adult humans undergoing hepatic resections due to various cancer diagnoses.

\section{Fluorescence and confocal microscopy}

CD31+ liver cells, enriched in LSEC, were resuspended in AIM-VTM medium (cat.no: 12055091; Gibco, Amarillo, TX, USA) and plated in 8 well Ibidi $\mu$-slides coated with quick coating solution (cat. no: cAP-01, Angio-Proteomie; Boston, MA, USA) at a density of $150,000-250,000$ cells $/ \mathrm{cm}^{2}$. The cells were incubated at $37^{\circ} \mathrm{C}$ in $5 \% \mathrm{CO}_{2}$ and $5 \% \mathrm{O}_{2}$. Cells were fixed for $30 \mathrm{~min}$ at room temperature (RT) using $4 \%$ buffered formaldehyde (FA) after 12$48 \mathrm{~h}$ in culture. Confocal images were captured using a Zeiss LSM800 system equipped with a 40X 1.2NA water immersion lens before and after treatment with TrueBlack ${ }^{\text {TM }}$ Lipofuscin Autofluorescence Quencher (cat.no: 23007; Biotium Inc., Fremont, CA, USA). Live and fixed cells were also imaged in a Nikon fluorescence microscope equipped with a Zeiss Axiocam.

\section{Imaging flow cytometry}

CD31+ LSEC enriched liver cells in suspension were lightly fixed in 4\% FA for $5 \mathrm{~min}$. The cell suspension (20 million cells $/ \mathrm{mL}$ ) was transferred to $5 \mathrm{~mL}$ tubes with cell strainer caps (BD Biosciences) before analyzed on an AMNIS ${ }^{\circledR}$ ImageStream $^{\mathrm{x}}$ MkII imaging flow cytometer (Luminex). Excitation lasers at $405 \mathrm{~nm}$, $488 \mathrm{~nm}, 561 \mathrm{~nm}$, and $642 \mathrm{~nm}$ were included to simultaneously capture fluorescent images in the emission range of $445-772 \mathrm{~nm}$ of in total 200 cells/patient.

\section{Immunolabelling}

Cultured CD31+ LSEC enriched liver cells were fixed as previously described, permeabilized with $0.2 \%$ Triton X-100 in PBS for $4 \mathrm{~min}$ and treated with TrueBlack ${ }^{\mathrm{TM}}$. Immune labelling was performed using goat anti-human mannose receptor (hMR) antibody (AF2534, R\&D systems, $4 \mu \mathrm{g} / \mathrm{mL}$ ), mouse anti-human Fc gamma receptor II (FcyRII) (FUN2, Biolegend, $5 \mu \mathrm{g} / \mathrm{mL}$ ), and mouse anti-human LAMP-1 antibody (H4A3, Developmental studies hybridoma bank, $0.3 \mu \mathrm{g} / \mathrm{mL})$. Primary antibodies were diluted in 1X PHEM buffer (60 mM PIPES, $25 \mathrm{mM}$ HEPES, 10 $\mathrm{mM}$ EGTA, and $4 \mathrm{mM} \mathrm{MgSO}_{4} \cdot 7 \mathrm{H}_{2} \mathrm{O}$ ) containing $1 \%$ bovine serum albumin (BSA) and incubated for $1 \mathrm{~h}$ at RT. Secondary antibodies were Alexa Fluor (AF) 488 donkey anti-goat IgG and AF488 donkey anti-mouse IgG (Invitrogen, $4 \mu \mathrm{g} / \mathrm{mL}$ ), diluted in 1X PHEM containing 1\% BSA and incubated for $30 \mathrm{~min}$ at RT. The fluorescent DNA stain DAPI (10 mM), incubated for $15 \mathrm{~min}$ at RT, was used for visualization of nuclei.

\section{Transmission electron microscopy}

Cultured cells were fixed in 4\% FA, 1\% glutaraldehyde (GA) and prepared as described by Kuo. ${ }^{13}$ In brief, fixed cells were scraped and pelleted before washing in 1x PHEM buffer, post fixed in $1 \%$ aqueous Osmium Tetroxide for $1.5 \mathrm{~h}$ and dehydrated in a graded series of ethanol, with dry acetone as an intermediate step, before infiltration in an Epon substitute [AGAR 100 resin (R1043), DDSA (R1051), MNA (R1081) and DMP-30 (R1065)] and polymerized at $60^{\circ} \mathrm{C}$ overnight. Ultrathin sections were made on a Leica EM UC7 Ultramicrotome using a Diatome diamond knife, mounted on carbon-coated formvar films on copper grids and contrasted with 5\% Uranyl acetate and Reynold's lead citrate. Images were taken using a Hitachi HT7800 microscope equipped with an Emsis Xarosa digital camera. 


\section{Results}

A large proportion of freshly isolated live and fixed CD $31^{+}$ enriched LSEC displayed strongly fluorescent granules in the cytoplasm, appearing in all channels of both conventional (RGB) and confocal fluorescence microscopy (405 nm/blue, $488 \mathrm{~nm} /$ green,
$561 \mathrm{~nm} / \mathrm{red}, 633 /$ far red) using normal laser intensity (Figure 1 $\mathrm{B}, \mathrm{C})$, although with less magnitude in the blue channel. The autofluorescent material was mostly located in the perinuclear area and appeared both as larger (up to $5 \mu \mathrm{m}$ in diameter) and smaller $(<1$ $\mu \mathrm{m}$ in diameter) granules. Imaging flow cytometry confirmed that the autofluorescence was detected in all available channels (Figure 1D).
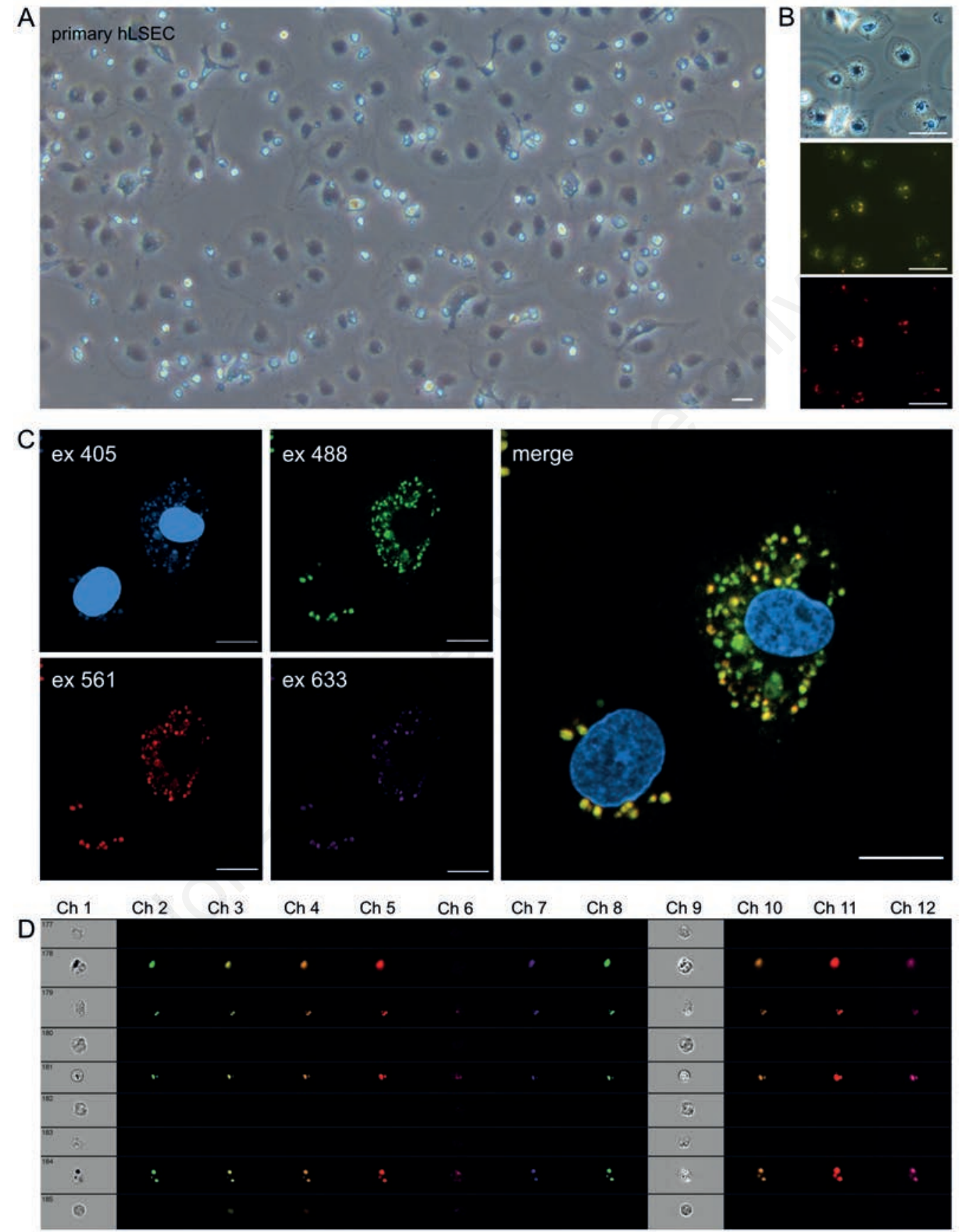

Figure 1. Autofluorescence in primary human LSECs. A) Conventional brightfield image of freshly isolated CD31 ${ }^{+}$LSECs in culture $17 \mathrm{~h}$ after plating; scale bar: $50 \mu \mathrm{m}$. B) Same area of cells imaged in a Nikon fluorescence microscope using brightfield (top), green filter (middle) and red filter (bottom); scale bar: $100 \mu \mathrm{m}$. C) A large proportion of non-treated CD31 ${ }^{+}$LSECs labelled only with DAPI shows autofluorescence in all four channels (blue, green, red, and far red) at normal laser intensity; scale bar: $10 \mu \mathrm{m}$; to watch a video of the autofluorescence through the entire spectrum of a Zeiss confocal microscope equipped with diode, Argon, DPSS and HeNe lasers, please visit Google drive at https://tinyurl.com/CD31autofluorescence. D) A large proportion of freshly isolated, non-treated, and lightly fixed CD31 ${ }^{+}$cells show autofluorescence in the 12-channel layout using AMNIS ${ }^{\circledR}$ imaging flow cytometry; the image is a representative view of 200 cells imaged. 
Time-dependent treatment with TrueBlack ${ }^{\mathrm{TM}}$ strongly reduced the autofluorescence, most efficiently in the near UV-area (413$483 \mathrm{~nm}$ ) (Figure 2). When applied for 2 min, TrueBlack ${ }^{\mathrm{TM}}$ efficiently quenched autofluorescent signals when applying moderate laser intensity $(0.5 \%$ laser gain, $<700 \mathrm{mV}$ amplitude) to the samples. However, when increased laser intensity was applied, the autofluorescence reappeared.

Subsequent immunostaining for specific cell markers was not impaired by the TrueBlack ${ }^{\mathrm{TM}}$ treatment. Immune labelling showed that the autofluorescent granules were present in cells that stained positively for two human LSEC markers, FcyRII (expressed in zone II/III) and the mannose receptor (Figure 3A). ${ }^{14-17}$ The perinuclear localization suggested that the granules could be associated with structures belonging to the lysosomal compartment and immunostaining revealed that the immunofluorescent material was located within LAMP-1 positive vesicles (Figure 3B).

\section{Discussion}

Autofluorescence in liver tissue is well known, ${ }^{1}$ but the morphological appearance and spectral characteristics of the wellestablished endogenous liver fluorophores $\mathrm{NAD}(\mathrm{P}) \mathrm{H}$ and vit $\mathrm{A}$ do not match the features of the autofluorescent granules observed in CD31+ LSECs. Vit A-induced autofluorescence in murine stellate cells is visible as large lipid droplets in the perinuclear area with increasing size in older animals, ${ }^{18,19}$ but in human cells it appears as smaller droplets scattered throughout larger areas of the cytoplasm. ${ }^{20}$ Furthermore, the spectrum of vit A-induced autofluorescence resides in the range of excitation 370-380 nm/emission 490$510 \mathrm{~nm}$ (blue region). ${ }^{6}$ In contrast, the autofluorescent granules in the CD31+ LSECs were visible throughout the entire emission range. Additionally, vit A-induced autofluorescence has high photolability and rapidly bleaches when exposed to light. ${ }^{1}$ The autofluorescent granules of the CD31+ LSECs did not show any signs of bleaching when excited with different light during fluorescence or confocal imaging.

LSECs have a high endocytic capacity and are known for their
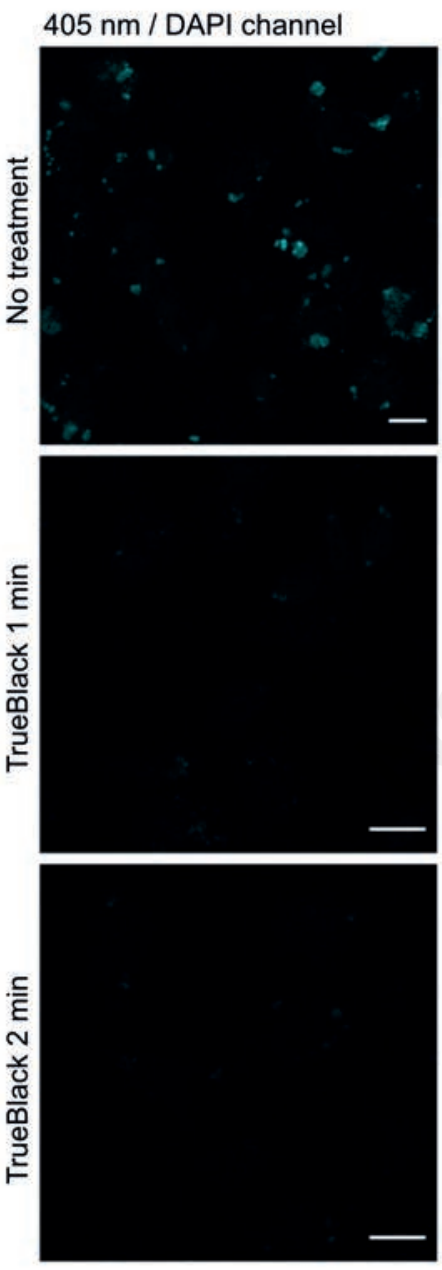

$488 \mathrm{~nm} /$ green channel
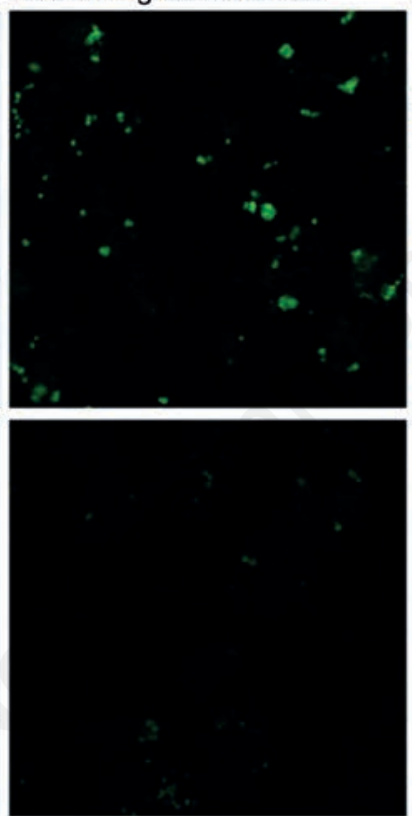

$561 \mathrm{~nm} /$ red channel
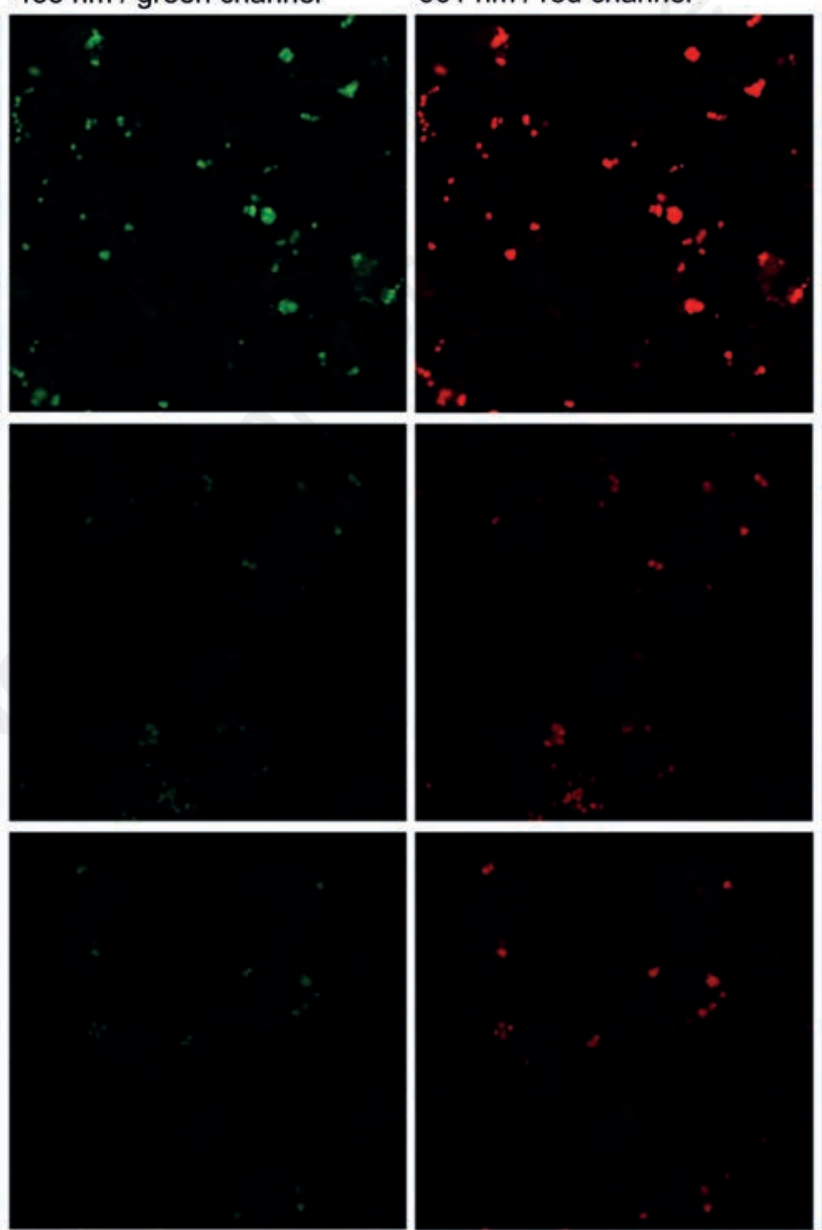

\section{$633 \mathrm{~nm} /$ far red channel}
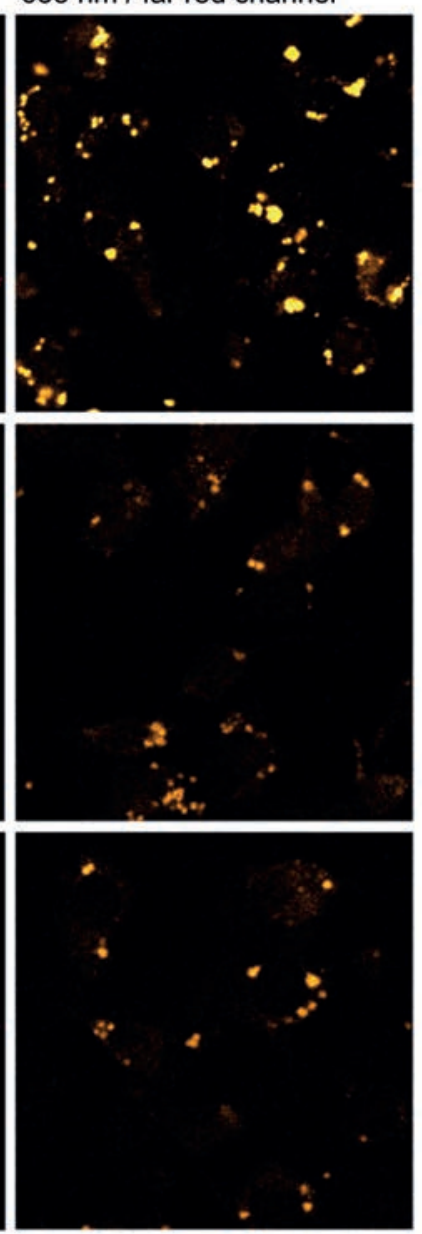

Figure 2. Quenching of autofluorescence. Treatment with TrueBlack ${ }^{\mathrm{TM}}$ lipofuscin autofluorescence quencher strongly reduced autofluorescence, most efficiently in the near UV-area. Traces of autofluorescence still remained in the red and far-red channels when applying TrueBlack ${ }^{\mathrm{TM}}$ for the period of time recommended by the manufacturer. Images are taken using only moderate laser intensity; scale bar: $10 \mu \mathrm{m}$. The effect of TrueBlack ${ }^{\mathrm{TM}}$ on autofluorescence quenching through the entire spectrum of a Zeiss confocal microscope equipped with diode, Argon, DPSS, and HeNe lasers can be observed at https://tinyurl.com/CD31TrueBlack. 
scavenging ability, removing macromolecular waste products from extracellular matrix turnover from the blood circulation. ${ }^{8,14}$ This, along with the fact that lipofuscins are remnants of tissue turnover products, suggests that LSECs accumulate this substance. In addition, a number of pathological conditions, including cancer, are associated with the accumulation of lysosomal pigments (ceroidtype lipofuscin) displaying properties similar to lipofuscin..$^{21,22}$ The liver tissue samples included in this study originated from adult patients with metastatic colon cancer (part of the disease-free resection margin) and the possibility of increased lipofuscin accumulation in cells isolated from this type of tissue cannot be ruled out.
The $\mathrm{pH}$ indicator phenol red, present in many cell culture media, is fluorescent when excited at $440 \mathrm{~nm} \cdot{ }^{23}$ Accumulation of phenol red in lysosomes could occur during culturing of the cells. The cells examined in the present work have been kept in culture for only a short period of time (12-24 h) and the cells analysed by the AMNIS ${ }^{\circledR}$ imaging flow cytometry were not cultured, supporting the notion that the autofluorescent material represents lipofuscin.

Although the autofluorescence can be quenched, there are some technical issues arising from this phenomenon. Quenching of the autofluorescence works best when applying normal laser intensities and will reappear if the laser intensity increases. When work-
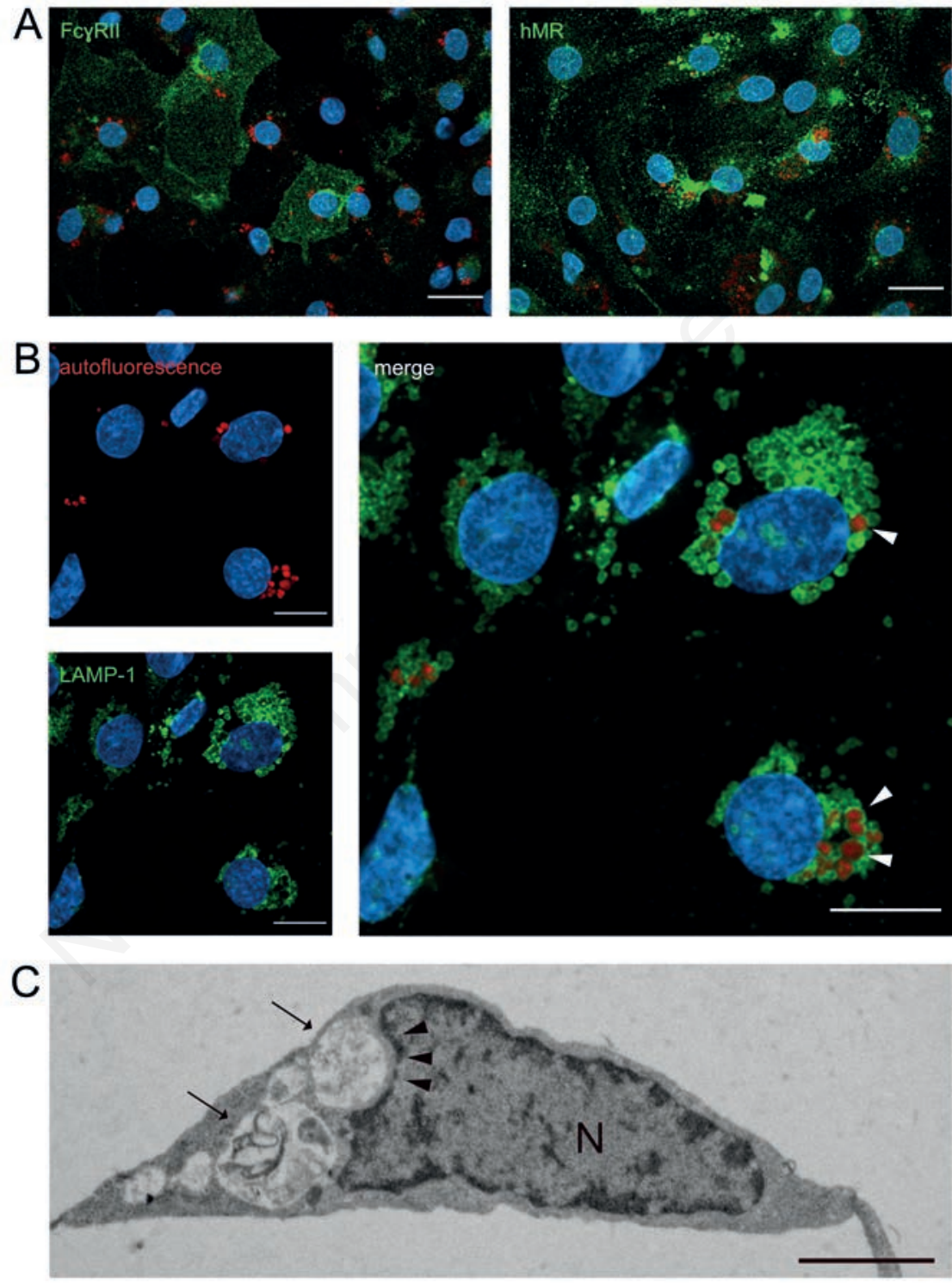

Figure 3. Autofluorescence and exogenous fluorophore detection in immunolabelled LSEC-marker expressing cells. A) CD31 ${ }^{+}$LSECs were cultured for $24 \mathrm{~h}$, fixed, treated with TrueBlack ${ }^{\mathrm{TM}}$ for 2 min and immunolabelled using (left) mouse anti-human Fc $\mathrm{RII}$ (green) and (right) goat anti-hMR (green) before being imaged using moderate laser intensity ( $0.5 \%$ laser gain, $700 \mathrm{mV}$ amplitude); the intensity of the red laser was increased to $1 \%$ laser gain, $780 \mathrm{mV}$ amplitude for the autofluorescence to reappear after TrueBlack-quenching (red); nuclei are stained with DAPI; scale bar: $20 \mu \mathrm{m}$. B) Lysosomal labelling with mouse anti-human LAMP-1 antibody (green) shows that the autofluorescent material (red) is located within LAMP-1 positive vesicles (arrow heads); cells were treated with TrueBlack ${ }^{\mathrm{TM}}$ for $1 \mathrm{~min}$ prior to immunolabelling to quench autofluorescence in the green channel while keeping some autofluorescence in the red channel; scale bar: $10 \mu \mathrm{m}$. C) TEM micrograph of a human LSEC displaying large perinuclear vacuoles (arrows) filled with material, displacing an indented (arrowheads) nucleus (N); scale bar: $2 \mu \mathrm{m}$. 
ing with low abundancy targets, this may introduce a conflict between visualizing the target and reappearance of the autofluorescence. Additionally, the lysosomal location of the autofluorescence may create technical challenges if cellular trafficking involving the lysosomal compartment is to be investigated.

\section{Acknowledgements}

The authors wish to thank the technical staff at CLINTEC, Karolinska University Hospital, Sweden for preparation of nonparenchymal cells from human liver resections, as well as the Advanced Microscopy Core Facility Platform, UiT - The Arctic University of Norway for technical assistance with preparation of TEM samples, confocal and flow cytometry imaging.

The publication charges for this article have been funded by a grant from the publication fund of UiT - The Arctic University of Norway.

\section{References}

1. Croce AC, De Simone U, Freitas I, Boncompagni E, Neri D, Cillo U, et al. Human liver autofluorescence: an intrinsic tissue parameter discriminating normal and diseased conditions. Lasers Surg Med 2010;42:371-8.

2. Shang L, Hosseini M, Liu X, Kisseleva T, Brenner DA. Human hepatic stellate cell isolation and characterization. J Gastroenterol 2018;53:6-17.

3. Brunk UT, Terman A. Lipofuscin: mechanisms of age-related accumulation and influence on cell function. Free Radic Biol Med 2002;33:611-9.

4. Robbins S, Contran RS, Kumar V. Pathologic basis of disease. 5th ed. W.B. Sounders Company; 1994.

5. Josefsen TD, Sørensen KK, Mørk T, Mathiesen SD, Ryeng KA. Fatal inanition in reindeer (Rangifer tarandus tarandus): pathological findings in completely emaciated carcasses. Acta Vet Scand 2007;49:1-11.

6. Croce AC, Bottiroli G. Autofluorescence spectroscopy and imaging: a tool for biomedical research and diagnosis. Eur $\mathrm{J}$ Histochem 2014;58;2461.

7. Elvevold K, Smedsrød B, Martinez I. The liver sinusoidal endothelial cell: a cell type of controversial and confusing identity. Am J Physiol Gastrointest Liver Physiol 2008;294:G391-G400.

8. Sørensen KK, McCourt P, Berg T, Crossley C, Couteur DL, Wake K, et al. The scavenger endothelial cell: a new player in homeostasis and immunity. Am J Physiol Regul Integr Comp Physiol 2012;303:R1217-R30.

9. Sørensen KK, Simón-Santamaría J, McCuskey RS, Smedsrød B. Liver sinusoidal endothelial cells. Compr Physiol
2015;5:1751-74

10. Croce AC, Ferrigno A, Vairetti M, Bertone R, Freitas I, Bottiroli G. Autofluorescence properties of isolated rat hepatocytes under different metabolic conditions. Photochem Photobiol Sci 2004;3:920-6.

11. Wake K. "Sternzellen" in the liver: perisinusoidal cells with special reference to storage of vitamin A. Am J Anat 1971;132:429-61.

12. LeCluyse EL, Alexandre E. Isolation and culture of primary hepatocytes from resected human liver tissue. In: P. Maurel, editor. Hepatocytes. Totowa: Humana Press; 2010. p. 57-82.

13. Kuo J. Electron microscopy: methods and protocols. Berlin: Springer; 2007.

14. Bhandari S, Larsen AK, McCourt P, Smedsrød B, Sørensen, KK. The scavenger funtion of liver sinusoidal endothelial cells in health and disease. Front Physiol 2021;12:e757469.

15. Martens JH, Kzhyshkowska J, Falkowski-Hansen M, Schledzewski K, Gratchev A, Mansmann U, et al. Differential expression of a gene signature for scavenger/lectin receptors by endothelial cells and macrophages in human lymph node sinuses, the primary sites of regional metastasis. J Pathol 2006;208:574-89.

16. Mousavi SA, Sporstøl M, Fladeby C, Kjeken R, Barois N, Berg T. Receptor-mediated endocytosis of immune complexes in rat liver sinusoidal endothelial cells is mediated by FcyRIIb2. Hepatology 2007;46:871-84.

17. Strauss O, Phillips A, Ruggiero K, Bartlett A, Dunbar PR. Immunofluorescence identifies distinct subsets of endothelial cells in the human liver. Sci Rep 2017;7:1-13.

18. D'Ambrosio DN, Walewski JL, Clugston RD, Berk PD, Rippe RA, Blaner WS. Distinct populations of hepatic stellate cells in the mouse liver have different capacities for retinoid and lipid storage. PloS One 2011;6:e24993.

19. Le Couteur DG, Warren A, Cogger VC, Smedsrød B, Sørensen KK, De Cabo R, et al. Old age and the hepatic sinusoid. Anat Rec 2008;291:672-83.

20. Werner M, Driftmann S, Kleinehr K, Kaiser GM, Mathé Z, Treckmann J-W, et al. All-in-one: advanced preparation of human parenchymal and non-parenchymal liver cells. PloS One 2015;10:e0138655.

21. Armstrong D, Koppang N. Ceroid-lipofuscinosis: a model for aging. In: RS Sohal, editor. Age pigments. Amsterdam: Elsevier; 1981. p. 355-82.

22. Reddy JK, Lalwani ND, Reddy MK, Qureshi SA. Excessive accumulation of autofluorescent lipofuscin in the liver during hepatocarcinogenesis by methyl clofenapate and other hypolipidemic peroxisome proliferators. Canc Res 1982;42:259-66.

23. Ettinger A, Wittmann T. Fluorescence live cell imaging. Methods Cell Biol 2014;123:77-94.

Received for publication: 5 October 2021. Accepted for publication: 1 December 2021.

This work is licensed under a Creative Commons Attribution-NonCommercial 4.0 International License (CC BY-NC 4.0).

(C) Copyright: the Author(s), 2021

Licensee PAGEPress, Italy

European Journal of Histochemistry 2021; 65:3337

doi:10.4081/ejh.2021.3337 